\title{
Comparison of the Traditional and Autonomous AGV Systems
}

\author{
Gabriel Fedorko ${ }^{1,}$ Stanislav Honus ${ }^{2}$, and Roland Salai ${ }^{1}$ \\ ${ }^{1}$ Technical University of Košice, BERG Faculty, Logistics Department, Park Komenského 14, 04001 \\ Košice, Slovakia \\ ${ }^{2}$ Technical University of Ostrava, Centre ENET, 17. listopadu 15, 70833 Ostrava-Poruba, Czech \\ Republic
}

\begin{abstract}
Automation is now an indispensable part of our world, which helps us produce more efficient, precisely and with lower costs. One of the major automation inventions were AGV vehicles, an automated guided vehicles, which meant a breakthrough in the internal logistics of many businesses. Today, these robots are nothing special, but their advanced functionality moves them to a higher level than before. This article describes one of their functionalities, which is an efficient and safe navigation while preserving the basic idea of their autonomy.
\end{abstract}

\section{Introduction}

The beginnings of AGV systems, in other words Automated Guided Vehicles, were in the 50 years of the 20th century [1]. AGV is automatically guided and drive vehicle or equipment which is replacing the transport and part of the handling of the material, part of the internal logistics activities [2].

Expansion of AGV's has continuously covered almost all sectors of business, production and industry. AGV`s have eliminated errors caused by human activity, because they work at a predefined standard, more precisely. Basic advantage is still cost reduction connected with personal cost $[3,4]$. The AGVs replaced initially simple logistics activities, such a transfer of material between the production halls, later between the lines, later were these vehicles able even replace the material handling by moving the material directly to the place of its consumption [5].

Basis of each AGV is control unit, security and guiding equipment, power supply and power unit [6]. The shape and accessories of each AGV are constructed according to the specialized activity for which the model is designed $[7,8]$. The simplest solutions replace function of classic logistics trains [9]. More specified AGVs, completely replace material handling from its autonomous picking and loading, through transportation and final delivery at place of consumption.

By increasing number of AGVs grow the necessity for their coordination, control and dispatch management. The usage of autonomous vehicles is moving out of the basic concept of autonomy.

*Corresponding author: gabriel.fedorko@tuke.sk 


\section{The principle of traditional AGV system}

The basic principle of the operation of traditional AGV system is in a pre-defined route placed on the floor or located in the floor, which is followed by reading device, which is a part of each traditional AGV.

In addition, other support devices are moving toward the basic functionality "tracking pre-defined route "to a higher level. We speak about safety bumpers, optical scanning devices, obstacle sensors, audio and visual warning devices, Wi-Fi connection, GPS modules, remote controls, communication via smartphone, camera systems and others.

The first AGV routes operated on an induction principle, which was created by the induced magnetic field in the floor. Later versions came to the color lines principle, so the AGVs tracked the color footprint on the floor, as well as the version where the route is made by magnetic tape on floor.

Newer versions use GPS navigation modules to navigate and are able to communicate with other ones and keep simple traffic rules. A very popular and affordable version is still a version using a magnetic tape.

\subsection{Magnetic guidance with obstacle sensor}

We consider this solution as a traditional and most advanced because of the easy application and use. The principle is as was mentioned above in the physical placement of the magnetic tape on the floor that the AGV reader will read. On the sides of the guiding magnetic tape are placed marks "tags" with opposite magnetism such as the basic magnetic tape route. These tags are also read by the AGV reading unit and processed by the control unit (Fig. 1).
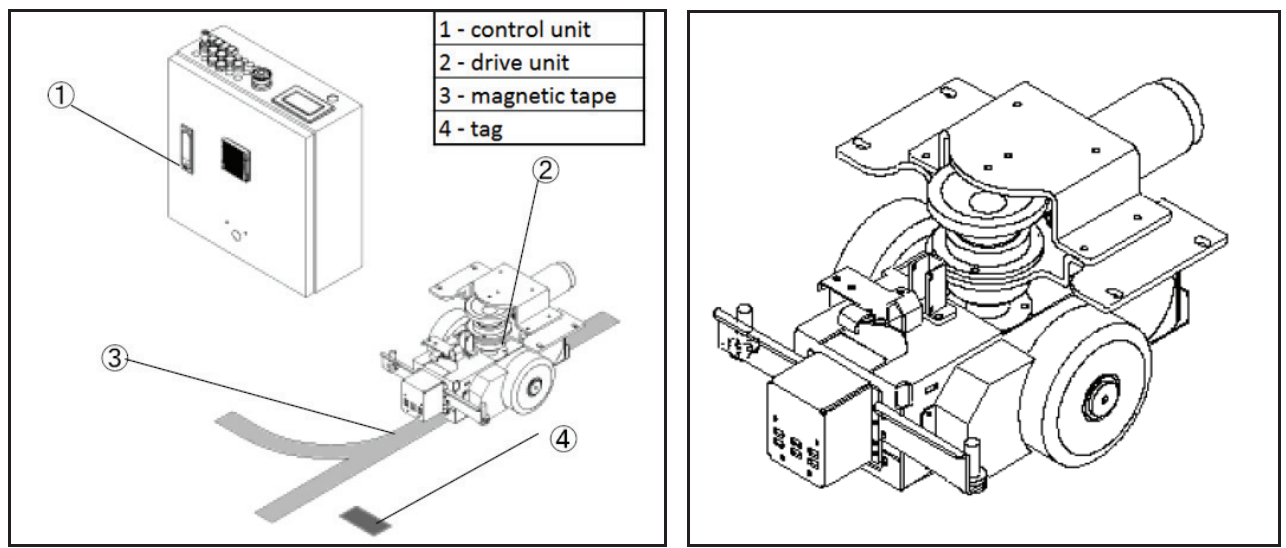

Fig. 1. Basic elements of AGV systems and AGV drive unit with magnetic tape and tags reader. Source: [10]

AGV works in a written program where each tag assigns parameters to which the AGV is to be set. These are parameters such as speed, turn right - left, warning signals, usage of the handling devices, obstacle sensor field settings, and others. Obstacle sensors play an important role in the proper autonomy of these AGVs.

\subsubsection{PBS Obstacle sensor}

Chosen model for comparison is the HOKUYOU obstacle sensor: PBS - 03JN. Sensor scans the space in the horizontal plane of its location, with 180 degrees radius and max 
scanned distance $20 \mathrm{~m}$. Mentioned PSB sensor communicates via PBS software configurator with a PC where it is possible to see an online scan of the space around area with free space and obstacles [11].
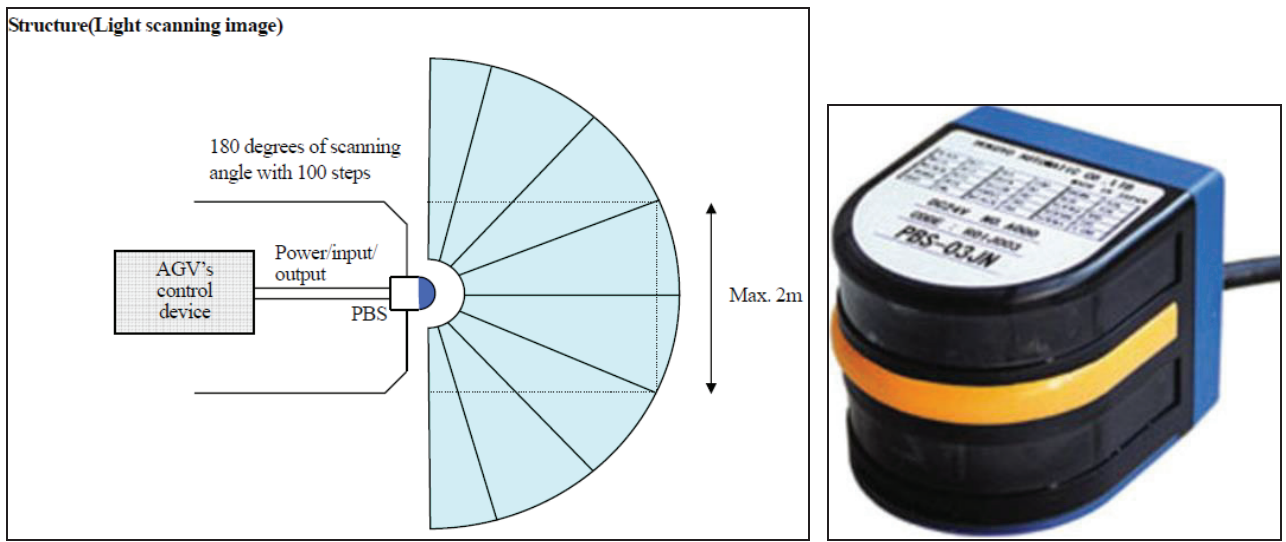

Fig. 2. PBS obstacle sensor detection guarantee range [12] and PBS obstacle sensor. Source: [13]

Using the PBS configurator, it is possible to create several areas of different shapes. These areas can be divided into fields where the pre-defined rules, how will AGV react when there will be presence of obstacle in the area and field. Colors fields are represented in this case with the yellow field farthest from the sensor, where visual and audio signaling occurs. The other is the orange field, which forces the AGV to slow down. There are also sound and visual alarms. The last field is a red field where the obstacle presence will cause AGV immediate stop.

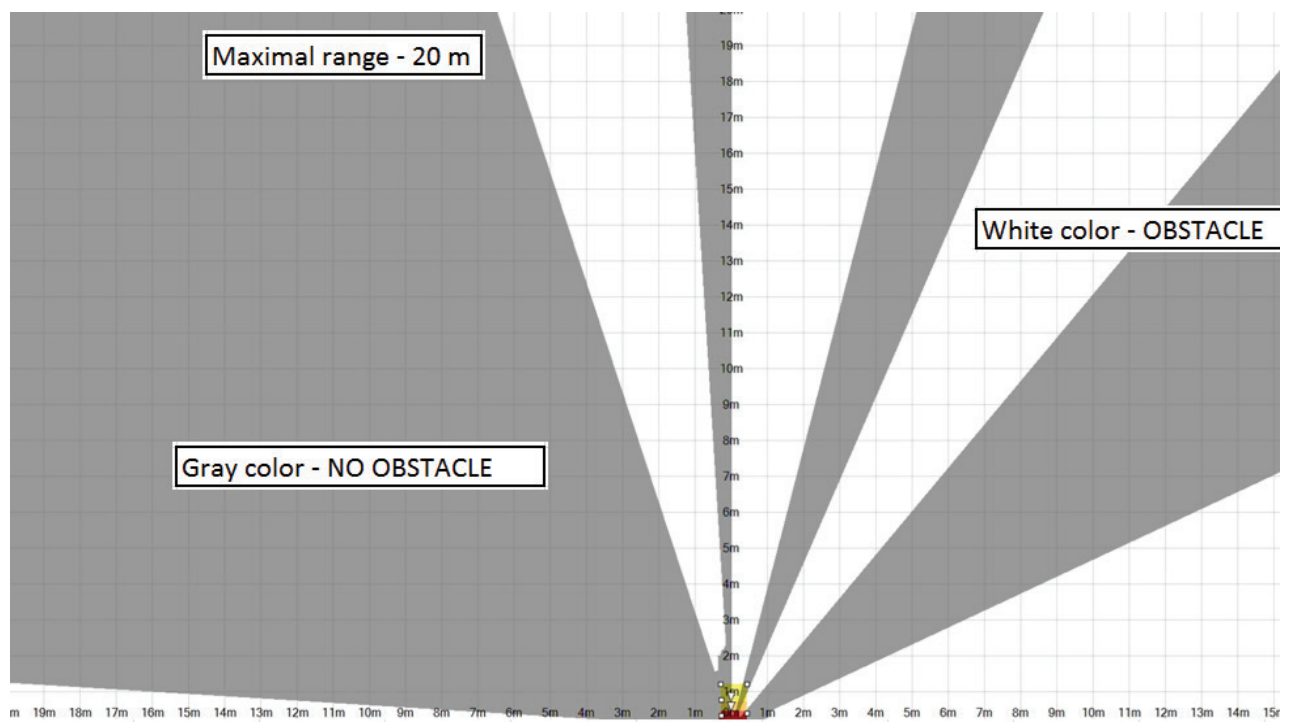

Fig. 3. PBS obstacle sensor maximal range and color indication - online data snapshot. Source: authors

AGV activity is restarted after removing the obstacle out from the red field of the area. This also the main disadvantage of these traditional AGV systems where the vehicle is strictly connected to fixed routes, and don't move toward until the obstacle is removed. If 
there is a higher number of vehicles AGV and their frequency on the same route, there may be a delay of several delivery units.

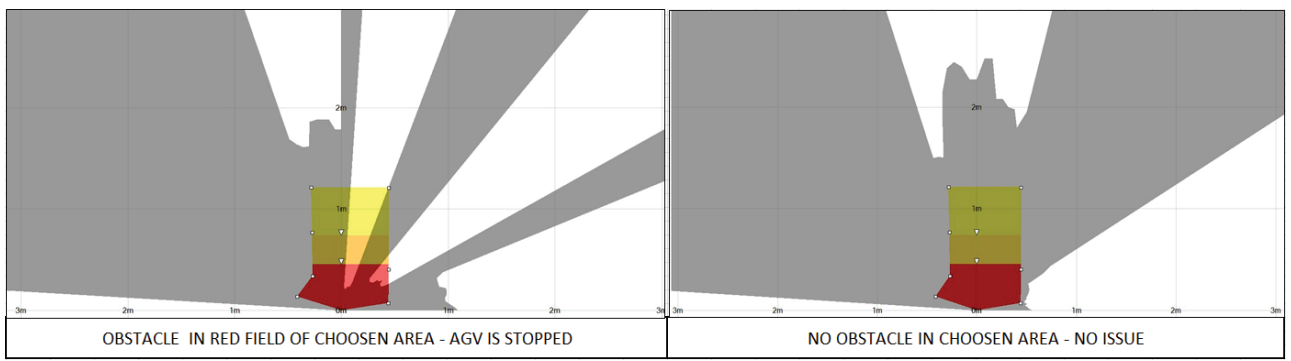

Fig. 4. PBS model area with and without obstacles. Source: authors

Another negative factor of magnetic tape is maintenance and replacement in case of damage, complicated replacement in case of new layout, and especially the risk of mismanagement in the case of a missing tag. In such cases when the tag is not present, AGV works as if it were in another part of the predefined route, and a collision or injury could easily happen.

\section{A modern solution through the Virtual Map}

The newest guidance systems are laser sensors, reading the tags placed on the pillars and walls in the production, from which AGV may identify its location, and also GPS guided vehicles. Compared and tested solution, which was built in cooperation with the Technical University in Košice, (project of Mr. Bačík).

The AGV was guided by a virtual map where the scanner scanned the space around and created a virtual map of the environment. In the map, with the simple click, we create the route on which we want $\mathrm{AGV}$ to move. Thus, the route realization time takes only a couple of minutes compared to the traditional magnetic tape, which in the first phase requires hours of work and settings. In the map are defined points that represent physical tags of the traditional system, this action in virtual map is also very fast. Points replace their function with magnetic tape.

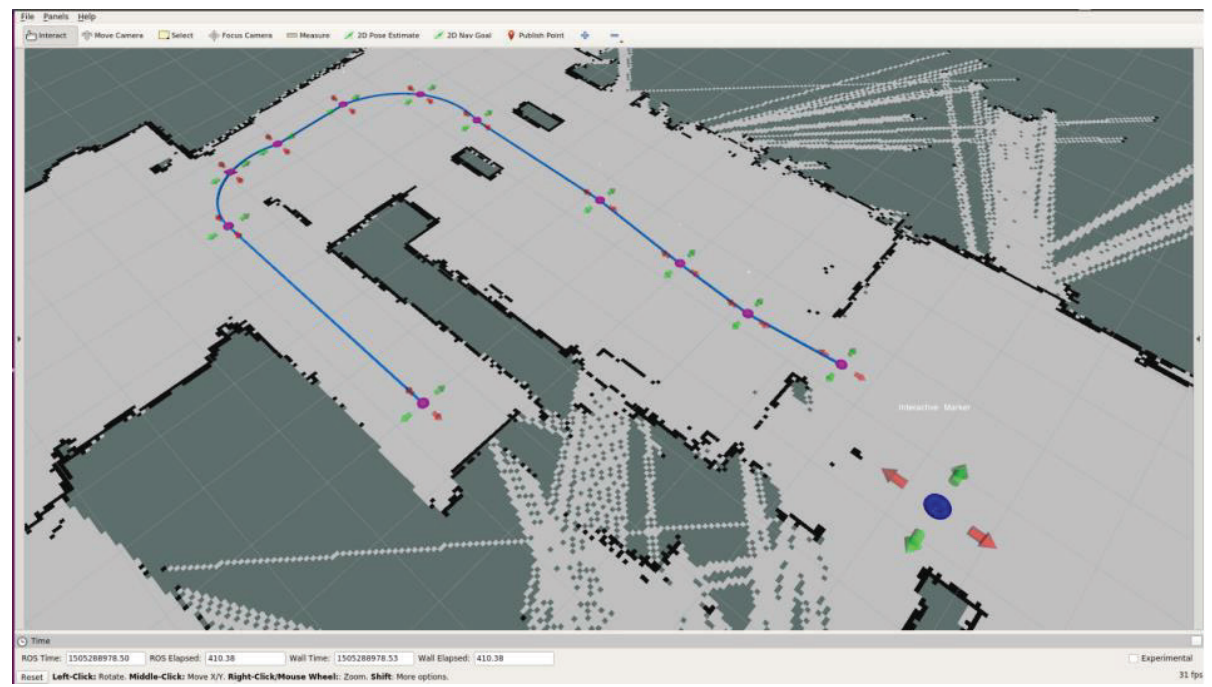

Fig. 5. Snapshot of virtual map with defined points. Source: authors 
In the environment where the vehicle movement is allowed, it is necessary to physically mark the starting point, or put the starting tags. By them can AGV vehicle identify its position in map like starting line and be prepared for round. During the movement, control unit via scanner compares the actual spare around with the virtual map, i.e., the movement is not so precise and fixed, with accuracy few centimeters as compared traditional system.

Some of the advantages are almost zero costs when new route is going to be created or updated after plant layout change, and no maintenance costs compare magnetic solution. Solution creates a virtual environment where it is possible to maneuver, and don't be fixed to route. It means that in the virtual map can be defined maximum maneuvering space in which the AGV can move in the moment when an obstacle is in the area of predefined route. AGV control unit create an alternative route using maximum manoeuvring space and if possible vehicle will go around the obstacle, and returns to the originally defined route, where it continues the assigned task.

Table 1. Basic factors comparison of traditional and autonomous systems. Source: [14]

\begin{tabular}{|c|c|c|}
\hline COMPARISON & $\begin{array}{c}\text { TRADITIONAL } \\
\text { VEHICLE AGV }\end{array}$ & $\begin{array}{c}\text { AUTONOMOUS } \\
\text { VEHICLE AGV }\end{array}$ \\
\hline MANEUVERING & $\begin{array}{c}\text { movement acc. to } \\
\text { guiding elements, } \\
\text { tag, color line, } \\
\text { magnetic tape etc. }\end{array}$ & free movement \\
\hline INTEGRATION & $\begin{array}{c}\text { expensive and } \\
\text { lengthy }\end{array}$ & easy and simple \\
\hline $\begin{array}{c}\text { OBSTACLE } \\
\text { DETECTION }\end{array}$ & stop and waiting & move around \\
\hline
\end{tabular}

\section{Conclusion}

AGV vehicles are part of enterprise logistics for more than 60 years and still expanding and developing very quickly. However, the the basic idea for which they were created as well as other robots is to simplify the work of man. Knowledge and experience gained from the development of autonomous AGVs also play an important role in the development of autonomous cars that will be part of our life in next year as AGVs are today.

This work is a part of these projects VEGA 1/0063/16, KEGA 018TUKE-4/2016.

This paper is supported by the research project "From horse-drawn railway to intermodal transport" within Visegrad Fund.

\section{References}

1. G. Ullrich, Automated Guided Vehicle Systems (Springer Berlin Heidelberg, Berlin, Heidelberg, Germany, 2015)

2. H. Neradilova, G. Fedorko, 12th international scientific conference of young scientists on sustainable, modern and safe transport, 638-643 (Elsevier science BV, Amsterdam 192, Netherland, 2017)

3. V. Molnar, K. Pacutova, ICTTE 2016 - Proceedings of the third international conference on traffic and transport engineering, 570-575 (Belgrade, Serbia, 2016) 
4. N. Brnjac, B. Abramovic, M. Maslaric, PROMET-TRAFFIC Transportation 22, 303307 (2010)

5. H. Neradilova, G. Fedorko, Open Engineering 6, 700-710 (2016)

6. R. Kampf, L. Lizbetinova, K. Tislerova, Open Engineering 7, $26-30$ (2017)

7. L. Bartuska, O. Stopka, Chovancova, J. Lizbetin, Transport Means - Proceedings of the 19th International Conference on Transport Means, 107-111 (Kaunas University of Technology, Lithuania, 2016)

8. R. Kampf, O. Stopka, I. Kubasakova, V. Zitricky, WMCAUS 2016 - World Multidisciplinary Civil engineering-Architecture-Urban planning Symposium 2016, 1538-1544 (Procedia Engineering 161, Elsevier science BV, Amsterdam, Netherlands, 2016)

9. J. Fabianova, P. Kacmary, V. Molnar, P. Michalik, Open Engineering 6, 270-279 (2016)

10. T.C. S.r.o.: Automaticky Navádený Vozík, Návod na údržbu (2017)

11. L. Aichikikai, Techno Systems Co: CarryBee K Type 1 AGV Construction Manual, ver 10.07.06, Available online: http://www.aiki-tcs.co.jp/carrybee?lang=en (2016)

12. L. Hokuyo, Automatic CO: Measuring Distance Type, Obstacle Detection Sensor PBS-03JN, Instruction Manual (2002)

13. M. Systems: Manu Systems, Available online: https://en.manu-systems.com/HOKPBS-03JN.shtml (2017)

14. Systechgroup: Systechgroup presentation on "Fórum praktickej logistiky, IPA, 20.9.2016 Gbel'any, Available online: http://systechgroup.eu/sk/2016/07/29/testicek/ (2016) 